Revista de Economia Política, vol. 41, no 1, pp. 23-43, janeiro-março/2021

\title{
Envelhecimento da população e desigualdade
}

\author{
Population aging and inequality
}

\author{
ELIANA CARDOSO* \\ THAIS PERES DIETRICH** \\ ANDRÉ PORTELA SOUZA***
}

RESUMO: O presente trabalho traça o perfil da população acima dos 65 anos no Brasil. Descreve o envelhecimento da população e as diferenças na expectativa de vida nas regiões com diferentes níveis de renda. Discute a renda e a distribuição de renda entre as pessoas acima de 65 anos e mostra que a distribuição de renda entre eles é mais igualitária do que entre a população com menos de 65 anos. Finalmente, ao rever alguns aspectos da discussão em torno da reforma da previdência, conclui com a observação da necessidade de uma agenda de treinamento e qualificação da mão de obra ao longo do ciclo de vida.

PALAVRAS-CHAVE: Envelhecimento da população; desigualdade; distribuição de renda.

ABSTRACT: This article outlines the profile of the population over 65 years old in Brazil. It describes the aging of the population and the differences in life expectancy in regions with different income levels. It discusses income and its distribution among people over 65 years old and shows that the income distribution among them is more egalitarian compared to the population under 65 years old. Finally, by reviewing some aspects of the discussion on pension reform, it concludes by perceiving the need for an agenda for training and qualification of the workforce throughout the life cycle.

KEYWORDS: Aging of the population; inequality; income distribution.

JEL Classification: D13; D63; J14.

\section{INTRODUÇÃO}

Política Nacional do Idoso: velhas e novas questões, organizado por Camarano et al. (2016), contou com a contribuição de 32 pesquisadores. O livro tem ca-

\footnotetext{
* Escola de Economia de São Paulo Fundação Getulio Vargas EESP/FGV, São Paulo/SP, Brasil. E-mail: eliana.anastasia@gmail.com. Orcid: https://orcid.org/0000-0002-1670-7292.

** Centro de Microeconomia Aplicada Fundação Getulio Vargas C-Micro/FGV, São Paulo/SP, Brasil. E-mail: thaispdietrich@gmail.com. Orcid: https://orcid.org/0000-0001-5095-0408.

*** Escola de Economia de São Paulo e Centro de Microeconomia Aplicada Fundação Getulio Vargas EESP/FGV, São Paulo/SP, Brasil. E-mail: Andre.portela.souza@fgv.br. Orcid: https://orcid.org/00000002-5988-2437. Submetido: 15/Julho/2019; Aprovado: 29/Abril/2020.
} 
ráter multidisciplinar e faz uma análise da Política Nacional do Idoso (PNI) e dos avanços obtidos em relação à sua proteção social. Inclui uma descrição das condições de vida da população idosa brasileira até 2014. Os autores definem o idoso como a pessoa com mais de 60 anos (de acordo com a PNI) e organizam a publicação em quatro partes: histórico da PNI, implementação, novas questões e perspectivas. Os autores concluem que houve progresso na melhoria de renda. Entretanto, argumentam que várias políticas ainda deixam a desejar, como, por exemplo, na área da saúde (apesar da expansão da cobertura do Sistema Único de Saúde) e na da educação (forma importante de integração dos idosos na vida social).

Este trabalho assume uma perspectiva diferente, ao recusar a conceituação da pessoa idosa como aquela definida na lei atual, ou seja, a de que é idosa a pessoa acima de 60 anos. Reconhece a velhice como fenômeno biológico, mas ao mesmo tempo descreve como a percepção da velhice vem mudando ao longo dos anos. Por isso, este trabalho prefere uma conceituação que nos permita diferenciar entre várias formas de envelhecer e discute a diferença entre o velho que tem recursos, se preparou para a aposentadoria e mantém uma vida ativa e o velho sem recursos e sem perspectiva de encontrar atividades que o insiram no mundo social.

O presente ensaio apresenta uma reflexão sobre o envelhecimento e uma análise sobre a distribuição de renda entre os idosos no Brasil. Ele tem como objetivo contribuir para o debate de políticas públicas voltadas para idosos no Brasil e, em particular, as políticas previdenciárias. Pretende pontuar alguns aspectos normativos desse debate que são relevantes nas escolhas dessas políticas públicas.

Para isso, inicia-se com uma discussão conceitual sobre envelhecimento. Em seguida, traça o perfil da população acima dos 65 anos no Brasil. Descreve o envelhecimento da população e as diferenças na expectativa de vida nas regiões com diferentes níveis de renda. Discute a renda e a distribuição de renda entre as pessoas acima de 65 anos e mostra que a distribuição de renda entre eles é mais igualitária do que entre a população com menos de 65 anos. Finalmente, ao rever alguns aspectos da discussão em torno da reforma da previdência, conclui com a observação da necessidade de uma agenda de retreinamento e qualificação da mão de obra ao longo do ciclo de vida.

\section{DEMARCANDO O CONCEITO DE ENVELHECIMENTO}

As sociedades que desejam implantar políticas públicas voltadas para os mais velhos devem, obviamente, definir quem são os idosos. As políticas públicas voltadas para os idosos, em geral, os definem a partir de uma idade de corte específica. No Brasil, a Política Nacional do Idoso classifica como velho o indivíduo com mais de 60 anos. Na Itália, os médicos recalcularam como 75 anos a idade a partir da qual uma pessoa é considerada idosa. Sabemos que a percepção da velhice vem mudando ao longo dos anos. Quais as dimensões relevantes para definir idosos? Embora idade seja certamente uma delas, quais devem ser os critérios para demarcar uma idade de corte? 
Traçar as fronteiras da velhice apresenta dificuldades, mesmo quando se considera a velhice como fenômeno biológico. Sem dúvida, a grande maioria dos velhos sofre, em maior ou menor grau, de menor agilidade e de mais doenças do que os jovens. O destino biológico acarreta consequências econômicas e a involução se atrasa ou se precipita segundo os recursos pessoais e sociais. Em algumas sociedades do passado, uma pessoa era velha aos 40 anos e em algumas comunidades contemporâneas apenas aos 80 . O significado da velhice depende do sentido que a sociedade confere à vida e da maneira pela qual uma sociedade se comporta em relação aos velhos.

A velhice tem também dimensão existencial, ao modificar a relação do indivíduo com o tempo e, portanto, com o mundo. Como em qualquer idade, a sociedade estabelece o status do idoso, definindo em boa medida o comportamento do velho e o dos outros em relação a ele.

A condição do velho depende do contexto social. Na sociedade próspera, há opções que garantem a situação material do velho e uma maior expectativa de vida. Nos grupos que vivem ao nível da subsistência, o velho é uma boca inútil. No passado, alguns desses grupos adotaram soluções como matar os velhos ou deixar que morressem. Outros grupos, entretanto, os honravam e tentavam lhes asseguravam um fim confortável.

Nas sociedades modernas persistem realidades diferentes. A situação do velho rico que se preparou para a última etapa da vida e dispõe de recursos financeiros difere não só da situação do velho com recursos que se deixou surpreender com sua nova realidade biológica, mas principalmente da situação do velho pobre sem recursos e sem assistência.

As diferentes percepções sobre velhice podem ser ilustradas pelas visões refletidas na literatura. Apesar da enorme variedade das experiências ao longo do tempo em diferentes sociedades, podemos separar pelo menos duas visões opostas da idade avançada. Uma amarga e pessimista, realçada por Simone Beauvoir, em A Velhice. Outra jovial e moderna, que tenta criar a ilusão de que os velhos poderiam se reinventar a cada dia. Em centenas de páginas, Beauvoir descreve a velhice a partir de informações sobre os velhos na França e em outras civilizações e as ilustra com imagens da literatura e da iconografia. Beauvoir argumenta que o tema da velhice foi quase sempre tratado de maneira estereotipada repetindo-se as mesmas comparações e adjetivos. Os clichês se perpetuam, em parte porque o velho sofre um destino biológico inescapável. Em parte porque, deixando de ser produtivo, eleitor e agente da História, o velho não nos interessa. Portanto, bastam clichês para exaltá-lo ou diminuí-lo Beckett e Shakespeare, entretanto, o representam como a encarnação da condição humana (e voltaremos ao tema mais tarde). Mas, em geral, o velho fica à margem da humanidade: não nos reconhecemos nele.

Amarga é a visão do "teatro do absurdo". Nas Cadeiras, de Ionesco, um velho casal, preso à lembrança engrandecida do passado, tenta trazer de volta os dias que se foram. Dão uma recepção à qual ninguém comparece, acolhem convidados in- 
visíveis e circulam entre cadeiras vazias. No fim, saltam pela janela, porque entendem que a vida não tem sentido. ${ }^{1}$

Em Fim de partida, Beckett mostra, entre uma e outra lata de lixo, um casal de velhos evocando amores passados. Beckett também trata com crueldade o desmoronamento da memória em Dias felizes. As lembranças aparecem em desordem, mutiladas, arruinadas. É como se nada tivesse acontecido e o presente emergisse do vazio. ${ }^{2}$ Ainda de Beckett, o herói já idoso do romance Molloy vê uma das pernas endurecer e perde metade dos dedos do pé. Arrasta-se. Rasteja. Ocupa-se com lembranças que desmoronam, nebulosas, inconsistentes, falsas. A vida é apenas a memória que temos dela, e a memória não vale nada. ${ }^{3}$

Para Beckett, a velhice desmascara os limites da condição humana, como em de Shakespeare. ${ }^{4}$ No começo da tragédia, inadaptado à realidade, Lear decide irrefletidamente partilhar seu reino entre as filhas e exige delas declarações verbais para medir a afeição de cada uma. Habituado, pelo fato de ser rei, aos mais arrebatados louvores, acredita nas palavras das duas filhas mais velhas. Teimoso e imperial, irrita-se com Cordélia, que recusa o jogo senil, e a deserda. As duas filhas hipócritas o julgam com cruel lucidez. Paralelamente, a cegueira de Gloucester, que se deixa convencer que o filho bom é um celerado e confia no filho traidor, confirma a interpretação da idade avançada não como idade da sensatez, mas da aberração.

Lear, condenado pela maldade das filhas mais velhas, erra a esmo. Demente, tendo perdido tudo, encarna a tragédia humana. No início do drama, ele se assemelha aos heróis shakespearianos entregues a uma paixão obstinada — ambição, ciúme, ressentimento — que os impele a funestas resoluções. Quando a miséria e o desvario revelam a Lear sua condição, perdido na loucura em meio à qual fulguram verdades, a vida revela-se uma aventura miserável. Shakespeare e Beckett concebem a velhice como a verdade a partir da qual se deve compreender o homem e o absurdo de sua existência.

A visão que contrasta com essa perspectiva pessimista encontra-se na interpretação benigna de Cícero em De Senectute..$^{5}$ Aos 63 anos, o senador compõe uma defesa da velhice, cujo intuito seria, talvez, defender a autoridade abalada do Senado. Os nobres não acreditavam em mais nada, a não ser em prazeres, tendo transformado o estoicismo numa ideologia conservadora: o mundo está em harmonia; tudo que é natural é bom; cada elemento deve satisfazer-se com seu lugar; é preciso respeitar o status quo. Embora Cícero admita que na miséria a velhice não pode ser suportável, nem mesmo para um sábio, ele não se ocupa dos miseráveis e sim

\footnotetext{
1 Tradução em português: Ionesco (2004).

${ }^{2}$ Traduções em português: Beckett (2010) e Beckett (2010).

3 Tradução em português: Beckett (1989).

${ }^{4}$ Tradução em português: Shakespeare (1997).

${ }^{5}$ Tradução em inglês: Cicero (2016).
} 
dos senadores. Cícero quer demonstrar que a idade, longe de desqualificá-los, aumenta suas capacidades.

Nessa linha, o famoso discurso Old Age do filósofo americano Ralph Waldo Emerson gaba os méritos e a serenidade da última idade. ${ }^{6} \mathrm{O}$ velho é feliz, diz ele, primeiro porque escapou de perigos múltiplos e já não tem o que temer: com a vida atrás de si, ela lhe pertence e ninguém pode roubá-la. E prossegue dizendo que o velho pode repousar: foram-se as dúvidas e as inquietações. Emerson generaliza a satisfação que sente com o próprio renome.

Nunca um escritor exaltou mais a velhice do que Victor Hugo. Ele deve ter pressentido que sua velhice seria o momento em que seu destino se realizaria com mais perfeição. Entre as antíteses que o encantavam, explorou a que opõe um corpo defeituoso a uma alma sublime. Viu a velhice como uma das encarnações dessa antítese, ressaltando o contraste romântico entre um corpo enfraquecido e um coração indomável.

Entre essas visões extremadas, $A$ arte de envelhecer de Montaigne recusa tanto a zombaria da velhice quanto sua exaltação. Montaigne admite que para aqueles que empregam bem o tempo, a experiência e a ciência crescem com a vida. Mas a vivacidade, a prontidão, a firmeza e outras características essenciais se enfraquecem ou desaparecem.

$\mathrm{Na}$ literatura brasileira, figuras de idosos na ficção incluem as três perspectivas. Sobre a velhice desprotegida e frágil, personificando a miséria humana, há o conto "O grande passeio" de Clarice Lispector. O retrato de Mocinha - uma idosa que vivia no Maranhão, onde perdeu a família e de onde foi levada para o Rio de Janeiro - mostra o abandono da velha. Mocinha sofre resignada até que, cansada, encosta a cabeça no tronco de uma árvore e morre.

Em oposição a esse retrato, uma forte personagem feminina se destaca no primeiro volume de O Tempo e o Vento de Erico Verissimo. D. Bibiana Terra Cambará não corresponde ao perfil das mulheres da sociedade patriarcal, mas é dona de persistência: resolve problemas sem muitos rodeios e não mede esforços para defender o que é seu. É uma velha mais próxima dos heróis de Victor Hugo do que dos velhos de Beckett.

A perspectiva cética e serena de Montaigne se revela no protagonista do $\mathrm{Me}$ morial de Aires de Machado de Assis. Nem velho decrépito, nem herói indomável, o conselheiro Aires - diplomata aposentado de 62 anos, narrador fleumático, impassível e sereno - relata as memórias dos anos 1888 e 1889. Seu tom desapaixonado pode ser indício autobiográfico do Machado de Assis, que morreria pouco depois da publicação do livro.

Em "The Harvard Study of Adult Development" - pesquisa longitudinal que integrou três coortes de homens e mulheres, avaliados continuamente durante seis décadas - uma romancista não nomeada escreve: "Ao contrário de todas as expectativas, envelheço. Aprendemos que a juventude é maravilhosa e a velhice um

\footnotetext{
${ }^{6}$ Emerson (1862).
} 
terror. Vejo o inverso. Levei sessenta anos para aprender a viver razoavelmente bem, para fazer o meu trabalho e lidar com as minhas inadequações”.

Essa escritora está entre os velhos que se mantêm ativos, uma realidade que a maioria dos velhos com pouca educação não alcançam. Simone de Beauvoir observa que o conselho de se preparar para a velhice não adianta quando a preparação consiste apenas em juntar dinheiro e escolher o lugar da aposentadoria. Mais vale viver uma velhice ativa. Essa possibilidade, entretanto, pertence aos privilegiados. $\mathrm{Na}$ última idade se cava mais profundamente o fosso entre eles e a imensa maioria dos homens. Comparando os velhos privilegiados e a maioria dos destituídos poderemos responder à pergunta sobre o que há de inelutável no declínio do indivíduo e em que medida a sociedade é responsável por esse declínio.

Esta reflexão torna claro que um aspecto relevante do envelhecimento, do ponto de vista econômico, e em particular previdenciário, é a perda da capacidade laboral. Em parte previsível, ela também tem aspectos idiossincráticos e o grau de proteção que uma sociedade devota ao idoso envolve critérios normativos.

\section{ENVELHECIMENTO DA POPULAÇÃO}

De todos os fenômenos contemporâneos, o menos contestável e mais fácil de prever é o envelhecimento da população. Em todos os países, o envelhecimento da população deriva dos mesmos fatores: a queda da mortalidade infantil (que contribui fortemente para o aumento da expectativa de vida ao nascer) e a queda da natalidade. $O$ envelhecimento da população não significa, portanto, que a longevidade (isto é, o limite de vida) tenha se estendido de forma acentuada. Este limite ainda se situa em torno dos 120 anos. Quando se diz que a população envelheceu, queremos dizer que a proporção de pessoas idosas na população total cresceu. A Tabela 1 mostra a composição etária da população brasileira.

Tabela 1: População estimada total e por faixa etária (Brasil - 1997, 2007, 2017)

\begin{tabular}{l|c|c|c}
\hline & 1997 & 2007 & 2017 \\
\hline População Total & 156.128 .003 & 189.951 .533 & 206.172 .340 \\
Idosos entre 65 e 74 anos* & 6.033 .594 & 8.523 .466 & 12.698 .043 \\
Idosos com 75 anos ou mais & 3.211 .306 & 5.261 .895 & 7.946 .865 \\
\hline
\end{tabular}

Fonte: Elaboração própria, PNAD 1997, 2017 e PNAD Contínua 2017. * Idosos a partir de 65 anos até 74 anos.

Segundo a PNAD Contínua, a população total do Brasil em 2017 era de 206 milhões de pessoas e, desse total da população, 10 por cento representam a população de idosos com 65 anos ou mais.

Observe-se que nos 20 anos entre 1997 e 2017 a participação de pessoas com 75 anos ou mais na população total dobrou de 2 por cento para 4 por cento. Houve, portanto, um aumento importante da expectativa de vida das pessoas que já tinham alcançado 60 anos ou mais. Mas o fenômeno mais importante por trás do envelhe- 
cimento da população é o aumento da expectativa de vida ao nascer. A Tabela 2 compara a expectativa de vida ao nascer e em diferentes idades no Brasil em 1998 e 2017. Nos últimos 19 anos, enquanto o aumento da expectativa de vida ao nascer subiu 8 anos (de 68 para 76 anos), a expectativa de vida para quem já completou 70 anos subiu apenas 4 anos (de 11 para 15 anos).

Tabela 2: Expectativa de vida por faixas etárias, Brasil 1998-2017

\begin{tabular}{c|ccccccc}
\hline & 0 anos & 2 anos & 5 anos & 40 anos & 60 anos & 70 anos & $\begin{array}{c}80 \text { ou mais } \\
\text { anos }\end{array}$ \\
\hline 1998 & 68.1 & 68.8 & 66.0 & 33.6 & 17.6 & 10.9 & 6.0 \\
2017 & 76.0 & 75.1 & 72.2 & 39.3 & 22.4 & 15.2 & 9.6 \\
\hline
\end{tabular}

Fonte: IBGE, Diretoria de Pesquisas (DPE), Coordenação de População e Indicadores Sociais (COPIS).

Para ilustrar como a expectativa de vida por faixa etária tem variado ao longo do tempo, a experiência do Estado de São Paulo, onde as estatísticas são mais abundantes, é ilustrativa. As taxas de mortalidade por idade no Estado de São Paulo em 2017, comparadas às de 1950, aparecem no Gráfico 1. Essas taxas indicam decréscimo rápido dos riscos de morte em todas as faixas etárias ao longo de mais de seis décadas. Em 1950, a população paulista apresentava esperança de vida ao nascer de 54,2 anos e, em 2017, esse indicador alcançou 76,2 anos. A duração média de vida dos paulistas aumentou 22 anos nesse período, em decorrência da redução dos riscos de morte, visível no deslocamento das curvas de taxas de mortalidade por idade. Observa-se que o decréscimo dos riscos de morte ocorreu em todas as faixas etárias, com intensidades distintas. A queda da mortalidade, entretanto, foi proporcionalmente mais intensa nos grupos etários mais jovens, principalmente abaixo de 15 anos.

Gráfico 1: Taxa de mortalidade por idade (Estado de São Paulo - 1950-2017)

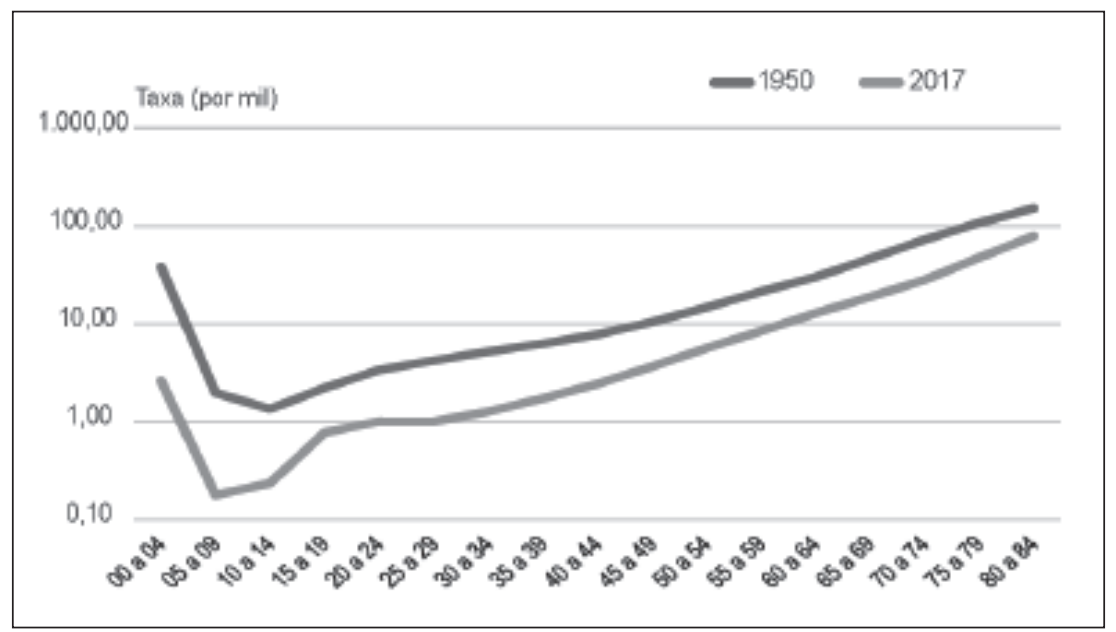

Fonte: Fundação Seade. 
A Tabela 3 apresenta a diferença das expectativas de vida entre as Unidades Federativas do Brasil. No Maranhão, a expectativa de vida ao nascer em 2017 é menos de 71 anos, enquanto excede os 79 anos em Santa Catarina. A expectativa de vida é mais baixa nas regiões mais pobres e o tamanho da taxa de redução da mortalidade infantil entre regiões tem um papel importante.

Tabela 3: Expectativa de vida, Brasil e UF (2017) ordenadas pelo menor - maior PIB per capita de 2016

\begin{tabular}{|c|c|c|}
\hline & 2017 & PIB per capita - $2016(\mathrm{R} \$)$ \\
\hline BRASIL & 76,0 & $30.411,30$ \\
\hline Maranhão & 70,9 & $12.264,28$ \\
\hline Piauí & 71,2 & $12.890,25$ \\
\hline Alagoas & 72,0 & $14.723,70$ \\
\hline Paraíba & 73,5 & $14.774,41$ \\
\hline Ceará & 74,1 & $15.437,75$ \\
\hline Pará & 72,3 & $16.689,55$ \\
\hline Acre & 74,2 & $16.837,69$ \\
\hline Bahia & 73,7 & $16.931,10$ \\
\hline Sergipe & 72,9 & $17.153,91$ \\
\hline Rio Grande do Norte & 76,0 & $17.168,60$ \\
\hline Pernambuco & 74,3 & $17.777,25$ \\
\hline Amapá & 74,2 & $18.329,19$ \\
\hline Tocantins & 73,7 & $20.598,73$ \\
\hline Roraima & 71,8 & $21.413,52$ \\
\hline Rondônia & 71,5 & $22.072,99$ \\
\hline Amazonas & 72,1 & $22.245,02$ \\
\hline Minas Gerais & 77,5 & $25.937,96$ \\
\hline Goiás & 74,3 & $27.135,06$ \\
\hline Espírito Santo & 78,5 & $27.487,45$ \\
\hline Mato Grosso do Sul & 75,8 & $34.247,79$ \\
\hline Paraná & 77,4 & $35.726,38$ \\
\hline Rio Grande do Sul & 78,0 & $36.206,54$ \\
\hline Santa Catarina & 79,4 & $37.140,47$ \\
\hline Mato Grosso & 74,5 & $37.462,74$ \\
\hline Rio de Janeiro & 76,5 & $38.481,96$ \\
\hline São Paulo & 78,4 & $45.542,32$ \\
\hline Distrito Federal & 78,4 & $79.099,77$ \\
\hline
\end{tabular}

Fonte: IBGE/Diretoria de Pesquisas. 
Na Tabela 3 é possível observar que os estados mais ricos são os que têm expectativa de vida ao nascer mais alta, ilustrando o fato de que a expectativa de vida varia com a renda.

A heterogeneidade das taxas de mortalidade infantil está presente até mesmo num estado rico como São Paulo. A taxa de mortalidade infantil média no estado é 10,74 óbitos infantis para cada mil nascidos vivos. Dos 645 municípios, entretanto, enquanto 182 não registraram nenhum óbito infantil, 273 tiveram taxas superiores à do Estado, e 163 municípios tiveram taxas com apenas um dígito, ou seja, inferiores a 10 óbitos por mil nascidos vivos.

Para entender como a renda, o conjunto de equipamentos públicos, a infraestrutura urbana e a qualidade de vida e bem-estar são centrais na determinação da mortalidade infantil e da expectativa de vida, o artigo "Como é viver no lugar onde se morre mais cedo" (publicado no site UOL em 4 de abril de 2017, com base nos dados da Fundação Seade) conta a experiência dos moradores de um dos 96 distritos do município de São Paulo. Uma única via, a avenida dos Metalúrgicos, concentra a maioria dos serviços disponíveis aos moradores de Cidade Tiradentes, na Zona Leste da capital. O distrito abriga o maior complexo de conjuntos habitacionais da América Latina, os prédios da Cohab (Companhia Metropolitana de Habitação) com cerca de 40 mil unidades, a maioria construída na década de 1980. Projetado para ser um "bairro-dormitório", hoje ele possui a décima maior concentração populacional em São Paulo e alguns dos piores indicadores, quando se pensa em qualidade de vida.

Em Cidade Tiradentes, a idade média ao morrer é menos de 54 anos, a mais baixa no Mapa da Desigualdade 2016, uma compilação de dados oficiais organizada pela ONG Rede Nossa São Paulo. Para efeito de comparação, o lugar com média mais alta para a idade média ao morrer na capital paulista é o bairro de Alto de Pinheiros, onde o número chega a mais de 79 anos de vida.

Alto de Pinheiros tem índice semelhante ao de um país como a Noruega, enquanto Cidade Tiradentes tem situação parecida com a de Serra Leoa, na África. Os distritos onde o tempo médio de vida é maior são os mais ricos. Segundo dados da Prefeitura de São Paulo, 15 por cento das famílias residentes de Cidade Tirantes estão em situação de alta ou muito alta vulnerabilidade.

Embora tanto a queda na taxa de natalidade quanto o aumento na expectativa de sobrevida têm como consequência o aumento na proporção de idosos na população, esses dois movimentos têm implicações distintas para políticas públicas, em geral, e previdenciária, em particular. A razão disso está nos impactos distintos sobre a taxa de dependência (razão crianças e idosos sobre adultos). Considerando que crianças e idosos consomem e não geram renda, uma maior taxa de dependência, para uma dada produtividade do trabalhador, implica uma menor renda per capita.

Uma redução permanente da taxa de natalidade tem apenas impactos transitórios sobre a taxa de dependência. Tudo mais constante, inicialmente esta redução leva a uma queda na taxa de dependência de crianças e não altera a taxa de dependência dos idosos (bônus demográfico). No segundo momento, quando es- 
sas primeiras crianças se tornam adultas, a taxa de dependência de crianças se reduz e volta ao seu nível inicial e a taxa de dependência de idosos aumenta (período de nível mais alto da taxa de dependência). Por fim, no terceiro momento, quando esses novos adultos se tornam idosos, a taxa de dependência de idoso se reduz e volta ao nível inicial. E, assim, a taxa de dependência retorna ao nível anterior ao aumento da taxa de natalidade.

Por sua vez, um aumento permanente na expectativa de sobrevida do idoso, tudo mais constante, aumenta permanentemente a taxa de dependência. Isso porque ele provoca um aumento permanente na proporção de idosos na população.

As implicações para políticas públicas são distintas. No caso de queda da taxa de natalidade, a questão central é como arcar com os custos das mudanças demográficas transitórias. Quem deve pagar por eles? Os custos deveriam ser arcados apenas pelos idosos do terceiro momento da mudança? Ou pelos adultos do segundo momento? Ou ainda por gerações futuras via endividamento público?

Já o aumento de expectativa de sobrevida implica mudanças permanentes de políticas. Pode-se ajustar, por exemplo, o período de aposentadoria.

Assim, as políticas sociais a serem adotadas em função do envelhecimento populacional dependem da natureza desse envelhecimento. As evidências recentes apontam que ambos as mudanças de taxa de natalidade e de expectativa de sobrevida ocorreram (e ocorrem) no Brasil e um mix de políticas sociais coordenadas que distribua seus custos de alguma maneira equitativa entre gerações e redistributiva entre grupos de uma geração parece ser o caminho mais sensato a ser percorrido (e.g., Turra, 2018; Turra et al., 2015; Turra et al., 2011; Vasconcelos e Gomes, 2012).

\section{QUEM SÃO OS VELHOS NO BRASIL}

Como pode ser inferido da Tabela 1 na seção anterior, em 2017 a população acima de 65 anos de idade no Brasil era formada por 20,6 milhões de pessoas, tendo aumentado de menos de 6 por cento da população brasileira total em 1997 para 10 por cento da população total em 2017. Como a expectativa de vida é maior entre as mulheres do que entre os homens, em 2017 as mulheres representavam 59,7 por cento da população brasileira com mais de 74 anos (que representava 4 por cento da população total).

Apenas uma minoria dos idosos vive na área rural. Cerca de 85 por cento da população com mais de 65 anos vive nos centros urbanos (PNAD Contínua 2017).

O perfil educacional da população brasileira idosa mudou ao longo dos últimos 20 anos. Em 2017, enquanto a população acima de 75 anos tinha em média apenas 4,6 anos de estudo, a população entre 65 e 74 anos de idade já tinha em média 6,3 anos de estudo. Em contraste, em 1997 a população acima de 75 anos possuía em média apenas 2,2 anos de estudo, enquanto a população entre 65 e 74 anos de idade possuía 2,9 anos de estudo. Em 2017, ainda existiam mais de 4,7 milhões de pessoas com mais de 65 anos que não sabiam ler, isto é, 19,1 por cento dos idosos entre 65 e 74 anos e 28,5 por cento dos idosos com 75 anos ou mais. 
Observe-se ainda que a expectativa de vida das mulheres é mais alta do que a expectativa de vida dos homens e que esta diferença vem caindo, como se vê nos Gráficos 2 e 3 abaixo. Em São Paulo, a Fundação Seade constata que, entre 2000 e 2008, a diferença entre a esperança de vida feminina e masculina caiu de 9 para 6,3 anos.

Gráfico 2: Expectativa de vida ao nascer (Brasil, 1998 - 2017)

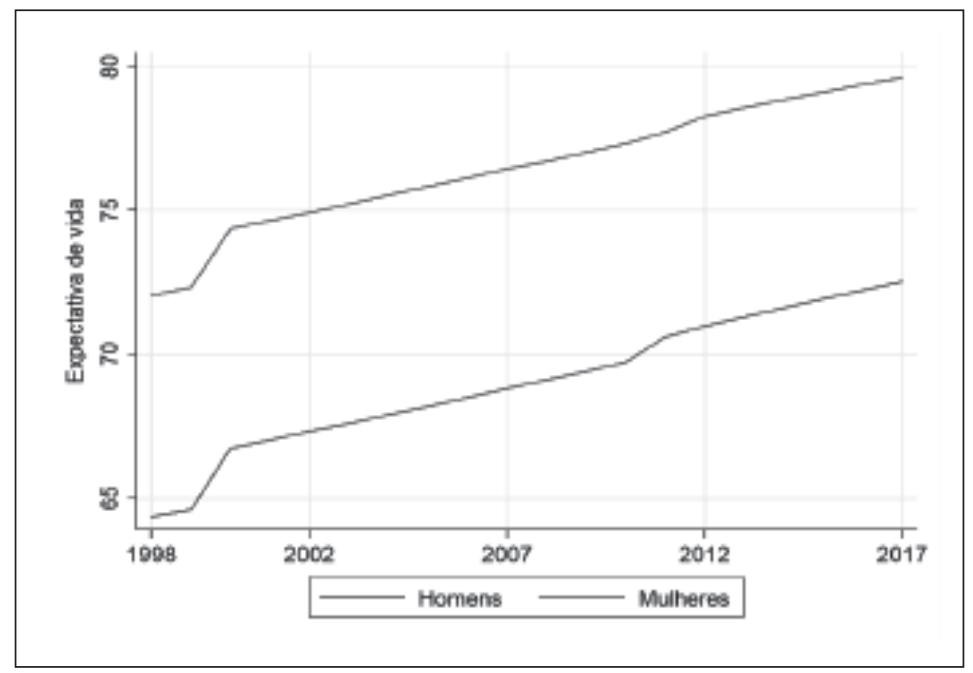

Fonte: Elaboração própria. Tábuas de mortalidade - IBGE (1998 - 2017).

Gráfico 3: Diferença de anos de vida a mais das mulheres (Brasil, 1998 - 2017)

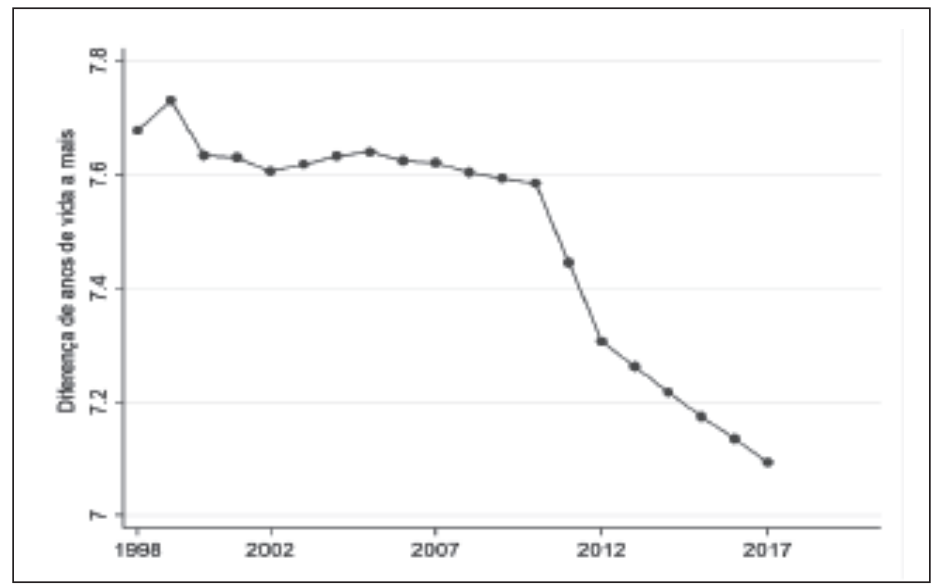

Fonte: Elaboração própria. Tábuas de mortalidade - IBGE (1998 - 2017). 


\section{RENDA E DISTRIBUIÇÃO}

A Tabela 4 mostra a fonte de rendimento dos idosos em 2017. A fonte mais importante de rendimentos são as aposentadorias e pensões. Oitenta por cento das pessoas entre 65 e 74 anos recebem aposentadoria ou pensão, seja como sua única fonte de renda, seja combinada com outras fontes de rendimento, inclusive trabalho. Este percentual sobe 89 por cento das pessoas com mais de 75 anos.

Tabela 4: Fonte de rendimento dos idosos (Brasil, 2017)

\begin{tabular}{|c|c|c|}
\hline Categoria & $\begin{array}{l}\text { Percentual dos idosos } \\
\text { entre } 65 \text { e } 74 \text { anos (\%) }\end{array}$ & $\begin{array}{l}\text { Percentual dos idosos } \\
\text { com } 75 \text { anos ou mais (\%) }\end{array}$ \\
\hline Somente aposentadoria ou pensão & 62,8 & 78,3 \\
\hline $\begin{array}{l}\text { Combinação de aposentadoria com trabalho } \\
\text { ou de aposentadoria com outras fontes }\end{array}$ & 17,2 & 10,6 \\
\hline Somente trabalho & 5,5 & 0,5 \\
\hline Somente outros rendimentos* & 4,8 & 5,3 \\
\hline Trabalho e outras fontes & 1,1 & 0,3 \\
\hline Nenhuma das categorias acima** & 8,6 & 5,0 \\
\hline
\end{tabular}

Nota:* Incluem benefícios como o Benefício Assistencial de Prestação Continuada (BPC-Loas) e outros programas sociais do governo, a doação ou mesada de pessoa fora do domicílio do idoso, aluguéis e arrendamentos.

**Idosos sem nenhuma fonte de renda individual (rendimento zero, embora possa viver em domicílio com renda positiva).

Fonte: Elaboração própria, PNAD Contínua 2017.

Como se pode observar na Tabela 5, a renda média da população acima de 65 anos de idade é mais alta do que a renda média da população entre 14 e 64 anos de idade em todos os anos. Em 2017, a renda média da população acima de 65 anos (R 2.004) é aproximadamente 41 por cento mais alta do a renda média da população entre 14 e 64 anos ( $R$ \$ 1.425). A discrepância é ainda maior entra os economicamente ativos. A renda média dos idosos economicamente ativos ( R \$ 4.054) é mais do dobro da renda média da população economicamente ativa entre 14 e 64 anos ( $R$ \$ 1.881). Entretanto apenas uma parcela pequena da população acima de 65 anos se mantém ativa. Os idosos ativos acima de 65 anos são apenas 15 por cento da população de idosos acima de 65 anos. E somente 5,5 por cento dos idosos acima de 75 anos se mantinham economicamente ativos em 2017. Esses números são consistentes com a hipótese de que apenas uma minoria privilegiada se mantém ativa e independente na velhice. 
Tabela 5: Renda Média (Brasil, 1997, 2007, 2017).

Milhões de pessoas e Renda média em reais de 2017

\begin{tabular}{|c|c|c|c|c|c|c|}
\hline & \multicolumn{2}{|c|}{1997} & \multicolumn{2}{|c|}{2007} & \multicolumn{2}{|c|}{2017} \\
\hline & $\begin{array}{c}\text { Milhões } \\
\text { de } \\
\text { pessoas }\end{array}$ & $\begin{array}{l}\text { Renda } \\
\text { média } \\
\mathrm{R} \$ \text { de } \\
1997\end{array}$ & $\begin{array}{c}\text { Milhões } \\
\text { de } \\
\text { pessoas }\end{array}$ & $\begin{array}{l}\text { Renda } \\
\text { média } \\
R \$ \text { de } \\
2007\end{array}$ & $\begin{array}{c}\text { Milhões } \\
\text { de } \\
\text { pessoas }\end{array}$ & $\begin{array}{c}\text { Renda } \\
\text { média } \\
\mathrm{R} \$ \text { de } \\
2017\end{array}$ \\
\hline População de 14 anos ou mais & 111,6 & 1.146 & 145,1 & 1.215 & 167,476 & 1.496 \\
\hline População entre 14 - 64 anos & 102,3 & 1.138 & 131,3 & 1.179 & 146,831 & 1.425 \\
\hline Idosos entre $65-74$ anos & 6,0 & 1.289 & 8,5 & 1.628 & 12,698 & 2.094 \\
\hline Idosos de 75 anos ou mais & 3,2 & 1.112 & 5,3 & 1.449 & 7,947 & 1.859 \\
\hline Idosos de 65 anos ou mais & 9,3 & 1.227 & 13,8 & 1.560 & 20,645 & 2.004 \\
\hline Ativa (de 14 anos ou mais) & 73,3 & 1.538 & 97,7 & 1.526 & 104,132 & 1.946 \\
\hline Ativa (14-64 anos) & 71,0 & 1.528 & 94,5 & 1.501 & 101,028 & 1.881 \\
\hline Ativa (65-74 anos) & 1,9 & 1.953 & 2,450 & 2.374 & 2,669 & 4.051 \\
\hline Ativa (75 anos ou mais) & 456,3 & 1.481 & 0,712 & 1.926 & 0,435 & 4.065 \\
\hline Ativa (65 anos ou mais) & 2,3 & 1.858 & 3,163 & 2.273 & 3,104 & 4.053 \\
\hline
\end{tabular}

Fonte: Elaboração própria, PNAD 1997, 2007 e PNAD Contínua 2017.

Tendo verificado que a renda média dos idosos se situa acima da renda média do resto da população, o que se pode dizer sobre a distribuição de renda entre os idosos em comparação com a distribuição de renda do resto da população?

O Gráfico 4 utiliza a função de distribuição acumulada para comparar a distribuição da renda da população de todas as fontes entre a população acima de 65 anos com a distribuição da renda população entre 14 e 64 anos. Há uma mudança nos últimos 20 anos. Em 1997, as duas curvas se cruzam em alguns pontos e não se pode dizer que uma domina a outra. Mas, em 2017, embora as curvas se toquem no nível de $\mathrm{R} \$ 1000$ por mês, em todos os outros níveis de renda a curva da distribuição de renda dos idosos com mais de 65 anos domina a curva de distribuição da renda da população abaixo dos 65 anos. A população acima de 65 anos apresenta uma frequência maior de rendimentos maiores em relação à distribuição de renda da população abaixo de 65 anos. 
Gráfico 4: Comparando a renda de todas as fontes para os idosos acima de 65 anos com a renda da população entre 14 e 64 anos (Brasil, 1997, 2007, 2017)

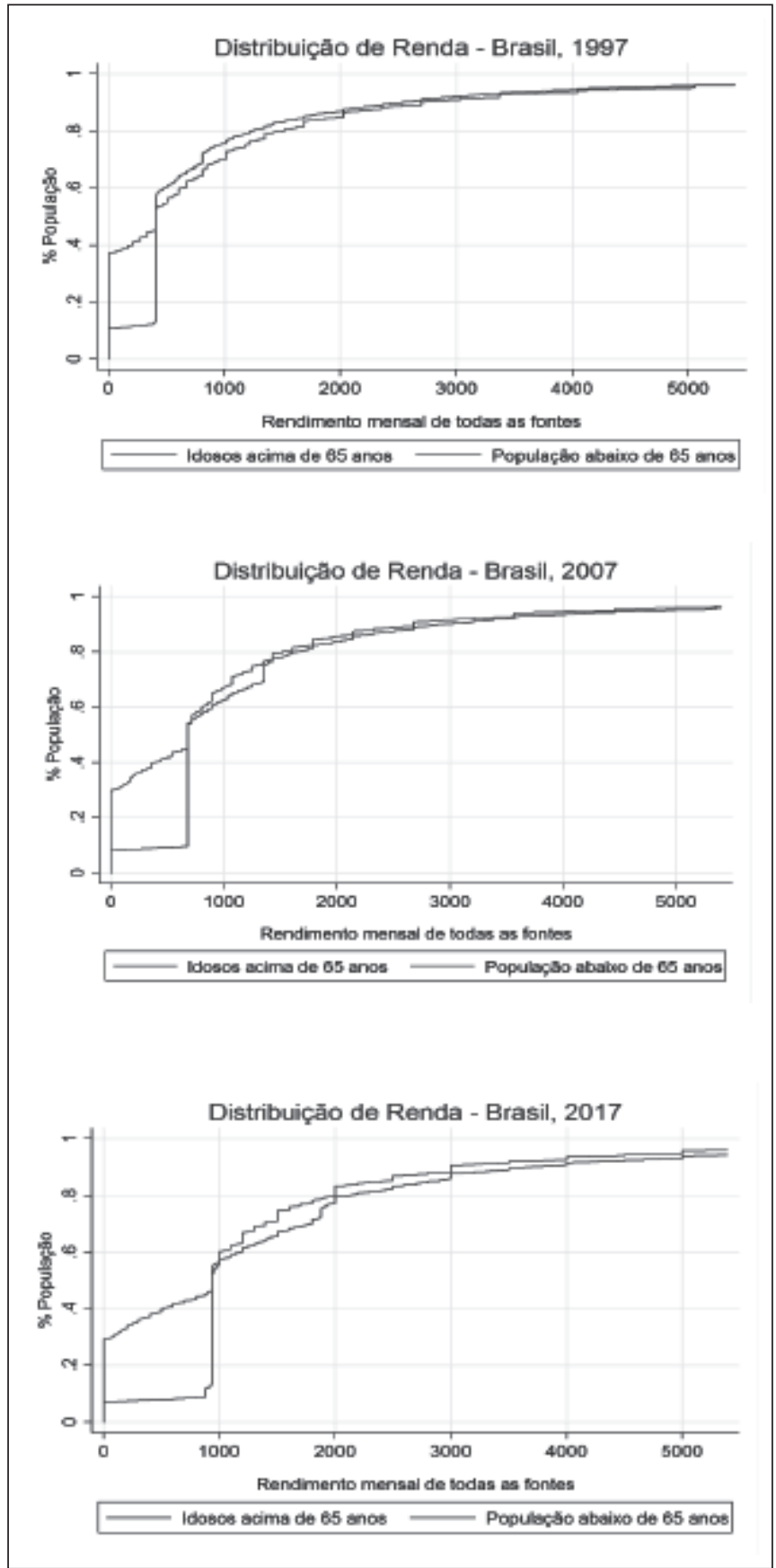

Fonte: Elaboração própria, PNAD 1997, 2007 e PNAD Contínua 2017. 
A renda mais alta e mais bem distribuída entre as pessoas acima de 65 anos em relação à renda das pessoas com menos de 65 anos fica evidente na comparação da renda domiciliar per capita com a renda dos idosos acima de 65 anos. $\mathrm{O}$ rendimento (medido no eixo horizontal) é maior para todas as frequências (porcentagem da população medida no eixo vertical). Como as aposentadorias e pensões são o componente mais importante dos rendimentos dos idosos, elas serão o tema da próxima seção.

Gráfico 5: Variação da distribuição de rendimentos per capita domiciliar comparada à distribuição dos rendimentos dos idosos. (Brasil, 2017)

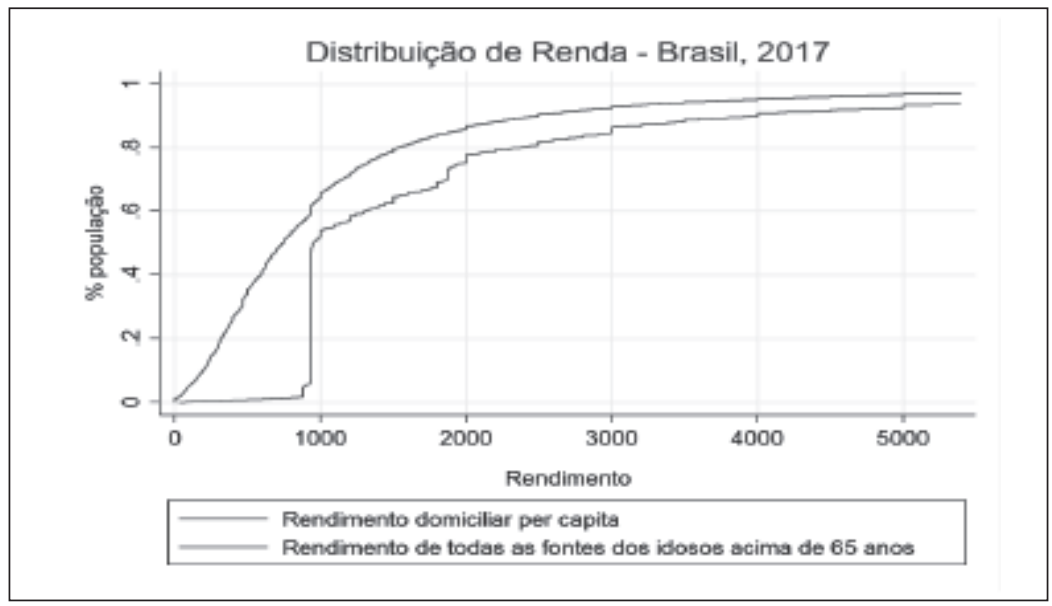

Fonte: Elaboração própria. PNAD Contínua 2017.

\section{EVOLUÇÃO DA DISTRIBUIÇÃO DE APOSENTADORIAS E PENSÕES ENTRE 1997 E 2017}

A evidência confirma que nosso sistema previdenciário é generoso. O relatório do Banco Mundial (2017) - Um ajuste justo: Análise da eficiência e equidade do gasto público no Brasil - critica o sistema previdenciário no Brasil por não ser focalizado nas pessoas mais pobres. Entretanto é importante observar que o mesmo relatório, usando dados da PNAD 2014, mostra que a pobreza haveria de disparar entre as pessoas acima de 60 anos se a renda da aposentadoria fosse excluída (o que não causa surpresa, pois já vimos que mais de 60 por cento da população acima de 65 anos tem a aposentadoria como única fonte de renda). Segundo o relatório, em 2014, para os indivíduos acima de 60 anos, a renda mediana domiciliar per capita era 4 vezes superior à linha da pobreza. E a renda média dos indivíduos com mais de 60 anos era de 6 a 7 vezes superior à linha da pobreza. A pobreza atingia menos de 5 por cento da população com mais de 60 anos, graças aos programas de transferências como as aposentadorias rurais e sociais do Benefício de Prestação Continuada de Assistência Social (BPC). 
$\mathrm{Na}$ quarta seção observamos que, em 2017, a distribuição de renda entre as pessoas acima de 65 anos era mais igualitária do que entre a população abaixo de 65 anos. Também verificamos que mais de 80 por cento dos rendimentos da população acima de 65 anos depende de aposentarias e pensões. Então deve ser verdade que a melhor distribuição de renda entre os idosos se deve a uma distribuição de rendimentos de aposentadorias e pensões que é mais igualitária do que a distribuição da renda da população abaixo de 65 anos.

O Gráfico 6 mostra que, de fato, a distribuição dos rendimentos de aposentadorias e pensões reduz a desigualdade de renda. Uma curva domina outra no sentido de Lorenz quando todos os seus pontos se situam mais próximos da linha de 45 graus no gráfico, que representa perfeita igualdade. A curva de Lorenz para a renda domiciliar per capita da população total incluindo as aposentadorias e pensões se encontra mais próxima da linha de 45 graus e, portanto, domina a curva de Lorenz para a distribuição da renda familiar per capita excluindo as aposentadorias e pensões.

Gráfico 6: Curvas de Lorenz (Brasil, 2017)

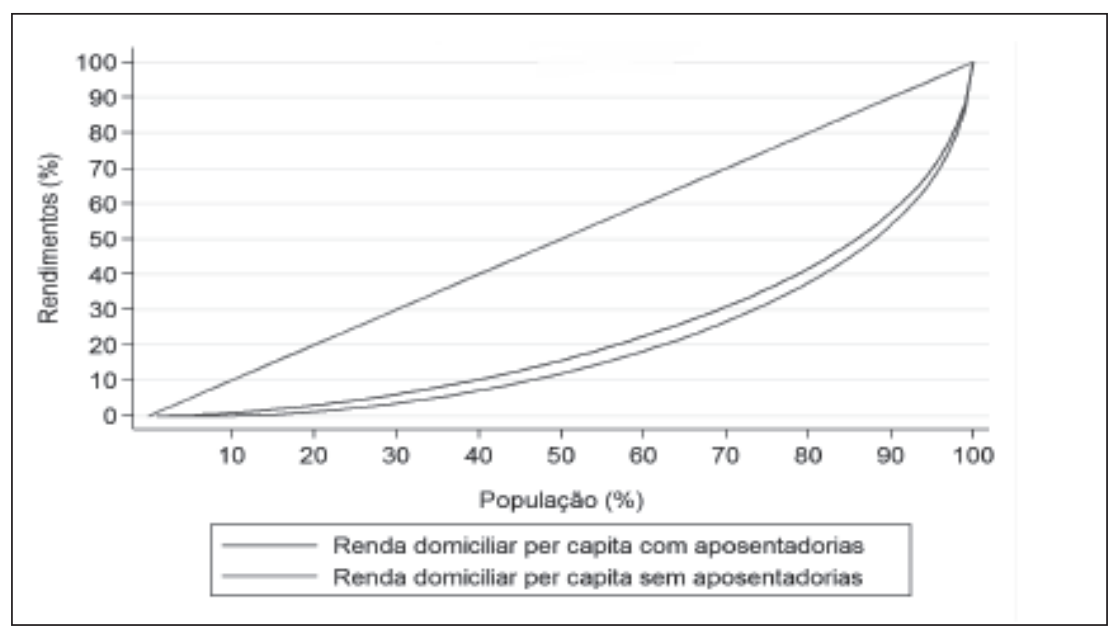

Fonte: PNAD Contínua 2017.

Estudos com exercícios similares que examinaram a distribuição de renda brasileira dos anos 1990 ou primeira década deste século encontraram resultados opostos. Por exemplo, Hoffman (2009) utilizou a PNAD 2007 e concluiu que as aposentadorias e pensões eram ligeiramente regressivas em termos distributivos. Outros estudos também chegaram a conclusões semelhantes (e.g., Hoffman (2003), Ferreira (2006)).

Parte da explicação dos resultados diferentes que encontramos mais recentemente reside no fato de que a desigualdade da distribuição dos rendimentos das aposentadorias e pensões vem melhorando ao longo dos últimos 20 anos, como se vê no Gráfico 7. 


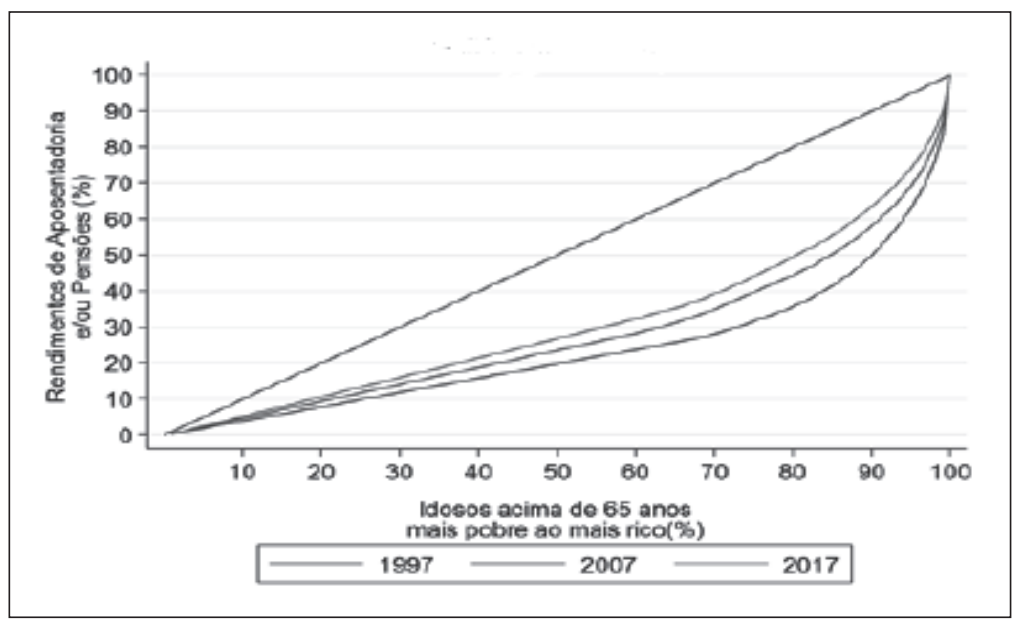

Fonte: PNAD 1997, PNAD 2007 e PNAD Contínua 2017.

Como, no sentido de Lorenz, a curva verde domina as outras, pois todos os seus pontos se situam mais próximos da linha de 45 graus no gráfico, podemos dizer que a distribuição das aposentadorias e pensões em 2017 é menos desigual do que a distribuição das aposentadorias e pensões nos anos anteriores. Comparando 1997 e 2007, a curva de 2007 domina a curva de 1997 e a curva de 2017 domina as anteriores.

O que permite que isso ocorra é que existem transferências de recursos públicos cobrindo a diferença entre receitas e desembolsos do sistema previdenciário. Chamamos de "transferência líquida para um determinado grupo" a diferença entre o valor presente do que aquele grupo contribui para sua aposentadoria e o valor presente do que recebe durante os anos de aposentadoria. O Banco Mundial chama parte dessas "transferências líquidas" (as transferências para as aposentadorias públicas) de "subsídios previdenciários" e os calcula como a diferença entre os benefícios médios e as contribuições médias por quintil de renda, usando os dados da PNAD 2014 e as regras do sistema previdenciário. As aposentadorias menores nos primeiros dois quintis das aposentadorias públicas recebem 18 por cento dos subsídios que sobem para 35 por cento dos subsídios totais no terceiro quintil, caem para 12 por cento no quarto quintil e voltam a subir para 35 por cento no quintil mais alto das aposentadorias públicas. ${ }^{7}$

\footnotetext{
${ }^{7} \mathrm{O}$ relatório do Banco Mundial também traça as curvas de Lorenz para a distribuição da renda per capita e para a distribuição dos "subsídios previdenciários" (Banco Mundial, 2017, p. 75). A curva de Lorenz desses subsídios se encontra acima da curva de Lorenz da distribuição de renda, permitindo a conclusão de que os subsídios são mais bem distribuídos do que a renda. Por outro lado, a curva de Lorenz da distribuição dos subsídios é extraordinária, porque, antes do sexto decil, ela cruza a linha
} 
Embora o relatório do Banco Mundial chame a atenção para a grande parcela de "subsídios previdenciários" atribuídos ao quintil mais alto de renda, a generalização do rótulo de regressivo para as transferências líquidas é controverso. Como 35 por cento dos subsídios cabem ao quintil do meio (que também recebe a maior parte das aposentadorias rurais e do BPC), a distribuição das transferências líquidas totais reduz a pobreza e melhora o perfil de distribuição entre a população mais velha em comparação com a distribuição de renda da população mais jovem. Mas, sem dúvida, a distorção representada pela grande parcela de "subsídios previdenciários" atribuídos ao quintil mais alto da distribuição de renda deveriam ser corrigidas numa reforma da previdência que, como a reforma em discussão no Congresso, imporia um teto uniforme para todas as aposentadorias.

Uma outra maneira de analisar os aspectos distributivos da previdência é comparar as taxas internas de retorno do sistema previdenciário para diferentes grupos populacionais. Afinal, as pessoas contribuem quando ativas para receberem suas pensões e aposentadorias quando inativas. Sob esse ângulo, a discussão de desigualdade passa da renda corrente para a renda ao longo do ciclo de vida. As diferentes regras do nosso sistema fazem com que distintos grupos tenham taxas de retorno distintas. Afonso e Fernandes (2005) estimaram as trajetórias esperadas de contribuições e de benefícios para diferentes coortes e grupos educacionais brasileiros e calcularam as taxas internas de retornos médias. Eles concluíram que o sistema previdenciário brasileiro é redistributivo, pois as taxas internas de retornos são maiores para os indivíduos com escolaridades mais baixas. Por exemplo, para os coortes nascidos entre 1920 e 2000 , a taxa interna de retorno para aqueles com escolaridade mais baixa era de $7,7 \%$ ao ano, enquanto para aqueles de escolaridade mais alta era de $6,1 \%$ a.a.

\section{REFORMA DA PREVIDÊNCIA}

O aspecto redistributivo apontado no parágrafo anterior provavelmente se manteria em muitas das reformas paramétricas em discussão. Fernandes et al. (2019) calcularam as taxas internas de retornos para grupos populacionais sob as regras da proposta original da reforma Temer. Entre outras medidas, ela impunha uma idade mínima de aposentadoria de 65 anos e um número mínimo de contribuição de 25 anos. Em todos os cenários considerados, a taxa interna de retorno dos menos escolarizados são maiores que as dos mais escolarizados. Por exemplo,

diagonal de 45 graus e se mantém acima dela durante o decil seguinte, apresentando um inchaço, antes de cruzar novamente a linha de 45 graus. O relatório do Banco Mundial conclui que os subsídios são regressivos, porque, enquanto os quintis de renda mais baixos recebem uma parcela menor dos subsídios, 35 por cento deles vão para o quintil mais alto de renda. Entretanto, é possível mostrar que, como outros 35 por cento dos subsídios cabem ao quintil do meio (que também recebe a maior parte das aposentadorias rurais e do BPC), a distribuição das aposentadorias e suas transferências melhora o perfil de distribuição entre a população mais velha. 
para o coorte de 25 anos de idade em 2015, no cenário de crescimento da produtividade de $2 \%$ a.a., a taxa interna de retorno das mulheres com até Ensino Fundamental 1 completo seria de cerca de $5 \%$, enquanto para as mulheres com educação acima do Ensino Médio completo seria de cerca de 3\% a.a.

Em geral, debates de reforma de previdência tratam quatro aspectos: (i) equilíbrio financeiro do sistema; (ii) justiça atuarial; (iii) escolha entre modelos atuarialmente justos e/ou sustentáveis no longo prazo; e (iv) transição entre sistemas. Os aspectos mais discutidos no Brasil giram em torno da questão do tamanho do déficit do sistema e da transição de um sistema para outro. A justiça atuarial e a escolha de modelos justos do ponto de vista atuarial e sua sustentabilidade aparecem menos, embora sejam igualmente importantes. Pois o sistema previdenciário deve garantir uma certa coerência e proporcionalidade entre contribuições e benefícios.

Vista sob esse último aspecto a discussão da reforma da previdência gira em torno da renda do indivíduo ao longo do ciclo de vida. De um lado, isso implica em desenhos de reformas que sigam princípios de justiça atuarial e repartição dos custos proporcionais entre as gerações (e.g., Fernandes et al. (2019)). De outro, coloca em evidência a geração de renda do indivíduo ao longo de sua vida. Em geral a idade com que um indivíduo atinge o máximo de renda é mais baixa entre a população menos escolarizada quando comparada com a população mais escolarizada. Os indivíduos sem instrução atingem o máximo de renda aos 50 anos de idade, já os indivíduos com 12 ou mais anos de escolaridade aos 58 anos. A partir daí a renda é declinante.

A análise da justiça do sistema previdenciário não se limita aos aspectos atuariais, pois o sistema precisa garantir uma renda mínima na velhice. Criar um sistema de solidariedade entre as gerações no qual idosos são providos com alguma renda e que, ao mesmo tempo, crie incentivos para que todos contribuam para o sistema é o desafio da reforma.

Uma boa reforma terá que criar um sistema sustentável e que possa contribuir para a correção de desigualdades que ainda persistem. O problema mais grave representado pelo sistema previdenciário no Brasil é que as contribuições da população ativa para o sistema de seguridade social não cobrem os gastos da previdência. Assim, o sistema previdenciário mostra déficits grandes e crescentes. Ele se transformou no fator-chave do desequilíbrio fiscal brasileiro. Sem uma reforma que torne o sistema previdenciário sustentável, qualquer tentativa de manter seus ganhos redistributivos pode se perder.

\section{OBSERVAÇÕES FINAIS}

Muitos países passaram por transições demográficas e envelhecimento populacional. O Brasil não é diferente. Talvez o que o torne distinto é a velocidade com que a transição demográfica vem ocorrendo. A rápida redução da taxa de fecundidade associada ao rápido aumento da expectativa de vida via redução da mortali- 
dade infantil colocou no topo da agenda o envelhecimento populacional e a questão da previdência.

O Brasil ainda é um país jovem, mas gasta com a previdência como um país velho. No começo de 2019, se projetavam déficits grandes e crescentes nos próximos anos. Sem uma reforma da previdência, o sistema não é sustentável no longo prazo. Parece inevitável que o sistema previdenciário tenha de se ajustar à realidade de rápida mudança demográfica.

Em Diário da guerra do porco, Adolfo Bioy Casares, que escreveu o livro em 1969, mostra uma Buenos Aires escura de relações sombrias em lugares claustrofóbicos. ${ }^{8}$

Uma guerra explode quando o governo tem dificuldades de pagar as aposentadorias e os jovens perseguem e atacam os velhos. O protagonista, Don Isidro, não sabe de que lado está nesse conflito. Já passou da idade dos jovens, mas não se considera velho. Em algumas colocações se coloca entre os idosos, quando, por exemplo, diz que "não há lugar para os velhos, porque nada está previsto para eles. Para nós". Desta forma, o romance reflete sobre o papel das pessoas que se tornaram "improdutivas", numa linha que também segue o pensamento de Simone de Beauvoir sobre a velhice. Mas a única alternativa à velhice é a morte. Ao guerrear os velhos, os rapazes matam "por ódio contra os velhos que serão". A solução dessa guerra só poderia ser encontrada num sistema previdenciário sustentável e numa velhice ativa.

Por último vale a pena enfatizar um aspecto das políticas públicas que se tornou primordial. $\mathrm{O}$ aumento da expectativa de vida associada às mudanças nas tecnologias do mundo do trabalho permite que a capacidade produtiva dos indivíduos se alongue. Faz-se imprescindível uma agenda de retreinamento e qualificação da mão de obra ao longo do ciclo de vida. O último relatório do Banco Mundial (Banco Mundial, 2019) destaca precisamente essa questão. As novas tecnologias requerem menos habilidades físicas e analíticas repetitivas e mais habilidades associadas a resoluções de problemas, trabalhos em grupo e adaptabilidade. Isto envolve uma agenda de treinamento e qualificação dentro e fora do local de trabalho com pedagogias e instrumentos adequados ao aprendizado do adulto, bem como modelos flexíveis que se adaptem ao estilo de vida do adulto.

\section{REFERÊNCIAS BIBLIOGRÁFICAS}

Afonso, L. E. e Fernandes, R. (2005). "Uma estimativa dos aspectos distributivos da previdência social no Brasil”. Revista Brasileira de Economia, vol. 59 (3): 295-334.

Banco Mundial (2017). Um ajuste justo: Análise da eficiência e equidade do gasto público no Brasil. Washington D.C.: Grupo Banco Mundial.

Banco Mundial (2019). “The Changing Nature of Work”. World Development Report 2019. Washington D.C.: World Bank Group.

Barro, Robert e Gary S. Becker (1989). "Fertility Choice in a Model of Economic Growth”. Econometrica. Vol. 57, No. 2. Mar., 1989, pp. 481-501.

${ }^{8}$ Bioy Casares (2010). 
Beauvoir, Simone de. (2018). A Velhice. Tradução de Maria Helena Franco Martins. Rio de Janeiro: Nova Fronteira.

Becker, Gary (1960). "An economic analysis of fertility". Demographic and Economic Change in Developed Countries. Princeton: Princeton University Press.

Beckett, Samuel (1989). Molloy. Tradução de Helena Souza. Rio de Janeiro: Biblioteca Azul.

Beckett, Samuel (2010). Fim de partida. Tradução de Fábio de Souza Andrade. São Paulo: Cosac Naify.

Beckett, Samuel (2010). Dias felizes. Tradução de Fábio de Souza Andrade. São Paulo: Cosac Naify.

Bioy Casares, Adolfo (2010). Diário da guerra do porco. Tradução de José Geraldo Couto. São Paulo: Editora Cosac Naify.

Camarano, Ana Amélia, Alexandre de Oliveira Alcântara e Karla Cristina Giacomin, orgs. (2016) Política Nacional do Idoso: velhas e novas questões. Rio de Janeiro: IPEA.

Cicero, Marcus Tulius (2016). How to grow old. Tradução de Philip Freeman. Princeton: Princeton University Press.

Emerson, Ralph Waldo (1862). “Old Age”. The Atlantic Monthly. January, 1862.

Ferreira, C. R.(2006), “Aposentadorias e distribuição da renda no Brasil: uma nota sobre o período 1981 a 2001. Revista Brasileira de Economia, v. 60, n. 3, p. 247-260, jul./set.

Fernandes, R.; Menezes-Filho, N.; Souza, A. P.; Komatsu, B.; Mentlik, G. M. (2019), "Reforma da Previdência: sustentabilidade e justiça atuarial”. Estudos Econômicos, v. 49, p. 423-463, 2019.

Fernandes, R., Menzes-Filho, N., Souza, A. P. (2019), "Sistema Brasileiro de Previdência Social: Uma Proposta de Reforma”, Encontro Nacional de Economia ANPEC, 2019.

Hoffman, R. (2009), "Desigualdade da distribuição da renda no Brasil: a contribuição de aposentadorias e pensões e de outras parcelas do rendimento domiciliar per capita”, Economia e Sociedade, Campinas, v. 18, n. 1 (35), p. 213-231.

Hoffmann, R. (2003), "Inequality in Brazil: the contribution of pensions". Revista Brasileira de Economia, v. 57, n. 4, p. $755-773$, out./dez.

Ionesco, Eugène (2004). A Lição/ As Cadeiras. Tradução de Paulo Neves. São Paulo: Editora Peixoto Neto.

Lispector, Clarice (1998). Felicidade Clandestina. São Paulo: Editora Rocco.

Machado de Assis (1997). Memorial de Aires. Rio de Janeiro: Editora Nova Aguilar.

Pesquisa Nacional por Amostra de Domicílios 2017. Rio de Janeiro: IBGE, 2007. Disponível em: ww2. ibge.gov.br/home/estatística/pesquisas/

Pesquisa Nacional por Amostra de Domicílios Contínua 2017. Rio de Janeiro: IBGE, 2017. Disponível em: downloads.ibge.gov.br/downloads estatísticas

Plomin, Robert (2018). Blue Print: How DNA Makes Us Who We Are, New York. Penguin.

Shakespeare (1997). O Rei Lear. Tradução de Millôr Fernandes. São Paulo: L\&PM Pocket.

Turra, C.M. (2018) “Os ajustes inevitáveis da transição demográfica no Brasil”. In: Alternativas para uma crise de múltiplas dimensões, Mônica Viegas Andrade e Eduardo da Motta e Albuquerque, eds.; revisão de Maria Clara Xavier. - Belo Horizonte: CEDEPLAR - UFMG, 2018.

Turra, C. M.; Queiroz, B. L.; Mason, A. (2015) "New estimates of intergenerational transfers for Brazil: 1996-2011”. NTA Project WP16-03. 2015. Disponível em: https://ntaccounts.org/web/nta/show/ Working\%20Papers.

Turra, C. M.; Queiroz, B. L.; Rios-Neto, E. L. G. (2011) "Idiosyncrasies of intergenerational transfers in Brazil”. In: LEE, Ronald; MASON, Andrew (eds.). Population aging and the generational economy: a global perspective. Northampton, MA: Edward Elgar Publishing, Inc, 2011. p. 394-407

Vaillant, George. (2002) Aging Well: Surprising Guideposts to a Happier Life from the Landmark Harvard Sudy of Adult Development. New York: Hachette Book Group.

Vasconcelos, A.M.N.; Gomes, M.M.F. (2012), "Transição demográfica: a experiência brasileira.” Epidemiologia e Serviços de Saúde, v. 21, n. 4, dez 2012, p. 539-548, Erico Verissimo (2018). O Tempo e O Vento. São Paulo: Companhia das Letras. 